\title{
Forced Degradation of Flibanserin Bulk Drug: Development and Validation of Stability Indicating RP-HPLC Method
}

\author{
Yik-Ling Chew ${ }^{1, *}$, Hon-Kent Lee ${ }^{1}$, Mei-Ann Khor ${ }^{1}$, Kai-Bin Liew ${ }^{2, \star}$, Bontha Venkata Subrahmanya \\ Lokesh $^{3}$, Gabriel Akyirem Akowuah ${ }^{1}$
}

${ }^{1}$ Faculty of Pharmaceutical Sciences, UCSI University, Kuala Lumpur, MALAYSIA.

${ }^{2}$ Faculty of Pharmacy, University of Cyberjaya, Selangor, MALAYSIA.

${ }^{3}$ Faculty of Pharmacy, University of Malaya, Selangor, MALAYSIA.

\begin{abstract}
Background: Flibanserin had been approved as the first drug by United State Food and Drug Administration (USFDA) for the treatment of female sexual interest/arousal disorder of any severity. However, the stability of this drug has yet to be studied extensively. Objectives: The objectives of this study were to optimize the stability indicating method and evaluate the stability of flibanserin under various forced degradation conditions, determine the order of the degradation kinetics, half-life and shelf life of flibanserin under certain stress conditions. The stability of flibanserin under various stress conditions which would reflect the important aspects of storage condition and excipients which should be avoided in the formulation of this drug substance into final drug products. Methods: Stability indicating method was developed using HPLC. It was validated according to $\mathrm{ICH}$ guideline for its linearity, precision, accuracy, robustness, LOD and LOQ. The forced degradation was performed under various stress conditions, namely acidic, alkaline and oxidative conditions $\left(\mathrm{H}_{2} \mathrm{O}_{2}, \mathrm{AIBN}\right.$ and $\left.\mathrm{FeCl}_{3}\right)$. LC-MS was utilised for identification of the degradation impurities, and the degradation kinetics was evaluated based on the kinetic models. Results: Degradation of flibanserin was noticed under oxidative conditions. Flibanserin was degraded under $\mathrm{H}_{2} \mathrm{O}_{2}$ oxidation at room temperature, while AIBN and $\mathrm{FeCl}_{3}$ at elevated temperature. Two $\mathrm{N}$-oxide impurities were identified under $\mathrm{H}_{2} \mathrm{O}_{2}$ oxidation. Flibanserin was degraded following the first-order kinetic under $\mathrm{H}_{2} \mathrm{O}_{2}$ and AIBN oxidation, while zero-order under $\mathrm{FeCl}_{3}$ oxidation. Half-life and shelf life of flibanserin under respective stress conditions were determined. Conclusion: It is concluded that the RP-HPLC method developed could be used as the stability indicating method in determination of flibanserin stability and its impurities. Flibanserin is sensitive towards oxidative degradation. The impurities and the order of the degradation kinetics were identified.
\end{abstract}

Key words: Forced degradation, Flibanserin, Degradation, Active pharmaceutical ingredients, HPLC, Impurities, oxidation, Degradation kinetics, Stability indicating method.

\section{INTRODUCTION}

Forced degradation also known as stress studies, stress testing, forced decomposition studies, stress decomposition studies can be performed in the third phase of regulatory submission process. ${ }^{1}$ It is very important for the production of new drug substances and new drug products especially when they are placed under extreme conditions. ${ }^{2}$ Early forced degradation studies are conducted to identify degradants produced and present in the final drug product. This would also allow the manufacturer to determine its shelf life. ${ }^{3} 5 \%$ to $20 \%$ is the acceptable limit for degradation of drug substances. $10 \%$ degradation is considered optimal for analytical validation in small pharmaceutical molecules. In other word, the acceptable stability limits of $90 \%$ was claimed to be common. ${ }^{2}$ Hydrolysis, oxidation, heat and
Submission Date: 17-06-2021; Revision Date: 19-08-2021; Accepted Date: 09-11-2021.

DOI: 10.5530/ijper.56.1.5 Correspondence: Dr. Yik-Ling Chew Faculty of Pharmaceutical Sciences, UCSI University. No. 1 Jalan Menara Gading, UCSI Heights-56000 Cheras, Kuala Lumpur, MALAYSIA.

E-mail: chew.yikling@gmail. com

Dr. Kai-Bin Liew

Faculty of Pharmacy, Cyberjaya University, Persiaran Bestari, Cyber 11, 63000 Cyberjaya, Selangor, MALAYSIA.

E-mail: liewkaibin@cyberjaya.edu.my

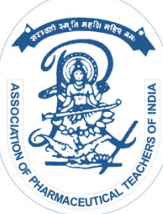

www.ijper.org 
photolysis are the major causes for the degradation of drug substances and products. ${ }^{4}$

Simple reaction orders such as zero-order, first-order, second-order and third-order are commonly involved in the studies of the stability of pharmaceuticals. ${ }^{3}$ Half-life is defined as the time taken needed by the drug to reduce its original drug concentration to half. Shelf life $\left(t_{90 \%}\right.$ or $\left.t_{95^{\circ}}\right)$ is defined as the time needed by the drug to reduce to $90 \%$ or $95 \%$ of its original concentration. ${ }^{5}$

Reaction between active pharmaceutical ingredients (API) with excipients often result in drug degradation. ${ }^{6}$ Hydrolysis, oxidation or specific interaction of drugs with reactive impurities in excipients are the common drugexcipient reactions. Reactive impurities are commonly found in excipients. These include lactose, povidone, crospovidone, microcrystalline cellulose hydroxypropyl cellulose, sodium croscarmellose, magnesium stearate, sodium starch glycolate, pre-gelatinized starch, stearic acid, silicon dioxide, and many more. ${ }^{6}$

Stability indicating method development is crucial in analysing the sample's stability and reliability in pharmaceutical industry. The physical and chemical properties of the drug and the detection sensitivity of the instrument were considered when choosing the suitable analytical method for drug stability study. Reversed phase-High Performance Liquid Chromatography (RP-HPLC) is popularly used as the stability indicating method due to its simplicity, versatility, minimal sample preparation, excellent recovery and high resolution. ${ }^{7}$ This technique is suitable for various types of compounds analysis, such as compounds with diverse molecular mass, polarity, thermal sensitivity and volatility. ${ }^{8}$ Besides stability studies, it is also commonly used as quality control and routine analysis of pharmaceutical products. Flibanserin had been approved as the first drug by United State Food and Drug Administration (USFDA) for the treatment of female sexual interest/arousal disorder of any severity. ${ }^{9}$ It is able to exert its actions by acting as an agonist at postsynaptic receptor and antagonist at 5-hydroxytryptamine $2{ }_{\mathrm{A}}\left(5-\mathrm{HT}_{2 \mathrm{~A}}\right)$ receptor. Flibanserin could regulate the dopamine and norepinephrine. It stimulates the postsynaptic $5-\mathrm{HT}_{1 \mathrm{~A}}$ receptors, causing the downstream release of dopamine and norepinephrine. It was reported that flibanserin was able to cause a gradual reduction in the level of serotonin, ${ }^{10}$ and inhibit the postsynaptic $5-\mathrm{HT}_{2 \mathrm{~A}}$ receptors in the prefrontal cortex, which could result in the reduction of serotonin. ${ }^{11}$ Flibanserin had also been used as the treatment of mental disorders such as Schizophrenia, depression, anxiety as well as Parkinson's disease. ${ }^{12}$

The objectives of this study were to optimize the stability indicating method, evaluate the stability of flibanserin under various forced degradation conditions, determine the order of the degradation kinetics, half-life and shelf life of flibanserin under certain stress conditions.

\section{MATERIALS AND METHODS}

\section{Chemicals and reagents}

Flibanserin ( $\geq 98 \%$, HPLC grade) and 1,1'-azobis (cyclohexane-carbonitrile) (AIBN) (98\%) were purchased from Sigma Aldrich (Steinheim, Germany). Anhydrous sodium hydroxide $(\geq 98 \%)$ pellets, anhydrous ferric (III) chloride (99.99\%), copper (II) sulfate pentahydrate $(\geq 98.0 \%)$ and acetonitrile (HPLC grade) were obtained from Merck KGaA (Darmstadt, Germany). Acetonitrile and ammonium acetate of MS grade were purchased from Supelco (Bellefonte, USA). Hydrochloric acid $(36 \%)$ and hydrogen peroxide $(30 \%, \mathrm{w} / \mathrm{w})$ were obtained from R\&M Chemicals (United Kingdom). Water was purified using Elga lab water purification system. 0.22 $\mu \mathrm{m}$ pore size filters were used to filter ultra-pure water and all solutions.

\section{Diluent, stock solution, calibration standards}

The mobile phase acetonitrile and ammonium acetate buffer $(10 \mathrm{mM})$ at the ratio of $60: 40(\mathrm{v} / \mathrm{v})$ was used as diluent. For the preparation of the stock solution (1 mg/mL), $5 \mathrm{mg}$ flibanserin was dissolved in $5 \mathrm{~mL}$ diluent, and the solution was sonicated for $5 \mathrm{~min}$.

$1 \mathrm{mg} / \mathrm{mL}$ stock solution was used to prepare standard flibanserin solutions ranging from $1-20 \mu \mathrm{g} / \mathrm{mL}$. Seven concentrations of flibanserin calibration standards prepared were 1, 2, 4, 5, 10, 15 and $20 \mu \mathrm{g} / \mathrm{mL}$.

\section{Forced degradation sample preparation \\ Acid hydrolysis}

In brief, $200 \mu \mathrm{L}$ of $1 \mathrm{M} \mathrm{HCl}$ solution was added into $50 \mu \mathrm{L}$ of $1 \mathrm{mg} / \mathrm{mL}$ flibanserin solution and the acid hydrolysis was performed for 7 days at room temperature and $70^{\circ} \mathrm{C}$. The reaction mixtures were topped up with diluents until $5 \mathrm{~mL}$ before subjected to HPLC analysis.

\section{Base hydrolysis}

In brief, $200 \mu \mathrm{L}$ of $1 \mathrm{M} \mathrm{NaOH}$ solution was added into $50 \mu \mathrm{L}$ of $1 \mathrm{mg} / \mathrm{mL}$ flibanserin solution and the base hydrolysis was performed for 7 days at room temperature and $70^{\circ} \mathrm{C}$. The reaction mixtures were topped up with diluents until $5 \mathrm{~mL}$ before the HPLC analysis.

\section{$\mathrm{H}_{2} \mathrm{O}_{2}$ oxidation}

$200 \mu \mathrm{L}$ of $3 \% \mathrm{H}_{2} \mathrm{O}_{2}$ solution was added into $50 \mu \mathrm{L}$ of $1 \mathrm{mg} / \mathrm{mL}$ flibanserin solution. The reaction mixtures were placed at room temperature up to $8 \mathrm{hr}$. Samples were collected at $0.5,1,2,4$, and $8 \mathrm{hr}$ for HPLC analysis. 
The reaction mixtures were topped up with diluents until $5 \mathrm{~mL}$ before the HPLC analysis. For Fourier Transformer Infrared (FTIR) analysis, the reaction mixtures were placed at room temperature for $48 \mathrm{hr}$ until all flibanserin had been degraded.

\section{Radical initiator oxidation}

In brief, $200 \mu \mathrm{L}$ of $10 \mathrm{mM} \mathrm{1,1'-azobiz(cyclohexane-}$ carbonitrile) (AIBN) solution was added into $50 \mu \mathrm{L}$ of $1 \mathrm{mg} / \mathrm{mL}$ flibanserin solution. The reaction mixtures were then placed at room temperature and $50^{\circ} \mathrm{C}$ for 5 days. The reaction mixtures were topped up with diluents until $5 \mathrm{~mL}$ before the HPLC analysis.

\section{Transition metal oxidation}

In brief, $200 \mu \mathrm{L}$ of $10 \mathrm{mM} \mathrm{FeCl}_{3}$ solution was added into $50 \mu \mathrm{L}$ of $1 \mathrm{mg} / \mathrm{mL}$ flibanserin solution. The reaction mixtures were placed at room temperature and $70^{\circ} \mathrm{C}$ for 7 days. The reaction mixtures were topped up with diluents until $5 \mathrm{~mL}$ before the HPLC analysis.

\section{Instrumentation \\ RP-HPLC condition}

The RP-HPLC analysis was performed on HPLC system (PerkinElmer, Inc, USA) container PDA detector. $250 \mathrm{~nm}$ was set as the UV detection wavelength. Chromatographic separation was performed on Luna $\mathrm{C}_{18}(4.6 \mathrm{~mm} \times 250 \mathrm{~mm}, 5 \mu \mathrm{m}$, Phenomenex, California, USA) and $25^{\circ} \mathrm{C}$ was maintained in the column. The gradient elution of two pumps were set up with acetonitrile and ammonium acetate buffer separately in two solvent reservoir bottles. $10 \mu \mathrm{L}$ was set as the injection volume.

The isocratic elution of flibanserin was performed with combination of acetonitrile and ammonium acetate buffer at the ratio of $60: 40(\mathrm{v} / \mathrm{v})$ with a flow rate of $0.5 \mathrm{~mL} / \mathrm{min}$. The total analysis time for each run was $20 \mathrm{~min}$.

\section{LC-MS condition}

Agilent 1290 Infinity LC system coupled to Agilent 6520 Accurate-Mass Q-TOF mass spectrometer with dual ESI source with software Agilent MassHunter Qualitative Analysis B.05.00 fitted with column Agilent ZORBAX Eclipse Plus $95 \AA$ ( $4.6 \times 150 \mathrm{~mm}$; $3.5 \mu \mathrm{m}$ ) was used to perform LC-MS analysis and the flowrate was maintained at $0.5 \mathrm{~mL} / \mathrm{min}$.

\section{Spectral measurements and data analysis}

IR spectrum of the reaction mixtures was captured using Nicolet $^{\mathrm{TM}}$ iS5 FTIR spectrometer equipped with iD5 ATR accessory featuring a top plate diamond crystal with a fixed angle of incidence of $42^{\circ}$, controlled by
OMNIC software. The reaction mixtures were put on the diamond crystal of the FTIR spectrometer and the IR spectra were recorded in absorbance mode from 4000 to $850 \mathrm{~cm}^{-1}$ at a spectral resolution of $4 \mathrm{~cm}^{-1}$.

\section{Validation of stability indicating method}

Validation of the proposed RP-HPLC method developed was performed as per ICH guidelines ${ }^{13}$ for linearity, repeatability, accuracy, precision, robustness, limit of detection (LOD) and limit of quantification (LOQ).

\section{Linearity}

Linearity was well-established by plotting peak area against the corresponding concentrations of flibanserin ranged from 1 to $20 \mu \mathrm{g} / \mathrm{mL}$ to get the linear regression equation and correlation coefficient. Seven concentrations and triplicates for each concentration were evaluated.

\section{Accuracy, precision and repeatability}

Accuracy of the method evaluate the closeness of agreement between the accepted reference value and value found. Three concentrations $(5,10$, and $15 \mu \mathrm{g} / \mathrm{mL})$ were analysed in triplicates. The percentage recovery (\% Recovery) and percent relative standard deviation (\% RSD) were measured.

The precision of the method was determined from flibanserin standards of the highest, middle and lowest concentrations in the established linearity range. Three flibanserin concentrations (5, 10 and $20 \mu \mathrm{g} / \mathrm{mL}$ ), determined in triplicates for each concentration to study for intra-day precision. The repeatability of standard concentration and measurement of peak area for flibanserin were expressed in percent relative standard deviation ( $\%$ RSD). $\%$ RSD value for inter-day precision was determined by analysing $20 \mu \mathrm{g} / \mathrm{mL}$ flibanserin solution, in triplicates for consecutive three days. The measurement of average peak area for flibanserin was expressed in terms of percent relative standard deviation (\% RSD) to set and meet the acceptance criteria.

\section{Limit of detection (LOD) and quantification (LOQ)}

Limit of detection (LOD) measures the detectable lowest analyte concentration that remains detectable in the sample. LOD was calculated using the following formula:

$\mathrm{LOD}=3.3(\sigma / \mathrm{S})$; where $\sigma$ is the standard deviation of intercept while $S$ is the slope of the calibration curve. Limit of Quantification (LOQ) measures the lowest quantifiable analytes concentration in the sample with suitable precision and accuracy. LOQ will be determined by specifying the lowest range which follows linearity 
equation. LOQ was calculated using the following formula:

LOQ $=10(\sigma / S)$; where $\sigma$ is the standard deviation of intercept while $S$ is the slope of the calibration curve.

\section{Robustness}

Robustness was performed by altering the conditions by 0.1 unit. The following conditions were used: (1) mobile phase flow rate changed from 0.9 to $1.1 \mathrm{mg} / \mathrm{mL}$;

(2) detection wavelength changed from $248-252 \mathrm{~nm}$; (3) mobile phase composition ratio changed from acetonitrile: ammonium acetate buffer $(62: 38, \% \mathrm{v} / \mathrm{v})$ to acetonitrile: ammonium acetate buffer $(58: 42, \% \mathrm{v} / \mathrm{v})$.

\section{Statistical Analysis}

All measurements were run in triplicates. One-way analysis of variance (ANOVA) using SPSS version 20 was used to perform statistical analyses. The results were presented as mean values $\pm \mathrm{SD}$ (standard deviations). Statistically significant was concluded when $P<0.05$.

\section{RESULTS AND DISCUSSION}

\section{HPLC conditions}

The analysis of flibanserin in health supplement using HPLC was previously performed by Low et al..$^{14}$ and Poplawska et al. ${ }^{15}$ Both studies used acetonitrile:water as mobile phase. Poplawska et al. ${ }^{15}$ added $0.1 \%$ formic acid into the mobile phase. However, it was known that formic acid could affect the deprotonation and signal suppression in LC-MS system. ${ }^{16}$ Therefore, ammonium acetate buffer ( $\mathrm{pH}$ 3.8) was used as the mobile phase in RP-HPLC. The method was validated according to ICH guidelines. ${ }^{17}$ Our RP-HPLC method developed using ammonium acetate was in comparison to formic acid, evaluated as per the ICH guidelines. It was shown that the method developed using ammonium acetate exhibited better performance in terms of precision, specificity, linearity, accuracy and robustness as per ICH guidelines.

The UV spectrum of flibanserin standard was scanned between 190 to $400 \mathrm{~nm}$, and the maximum absorption wavelength $\left(\lambda_{\max }\right)$ were $250 \mathrm{~nm}$ and $282 \mathrm{~nm} . \lambda_{\text {max }} 250 \mathrm{~nm}$ was selected as the detection wavelength in HPLC based on its sensitivity and absorption limit. The column performance and the retention time of flibanserin analysed using Phenomenex $\mathrm{C}_{18}$ was compared to Hypersil Gold and Spherisorb ODS2 using the same elution profile. Flibanserin was eluted with the best retention time in Phenomenex $\mathrm{C}_{18}$ as compared to Hypersil Gold and Spherisorb ODS2.

Optimised chromatographic conditions were mobile phase constituted of acetonitrile and ammonium acetate buffer with the ratio $60: 40(\mathrm{v} / \mathrm{v})$ with $\mathrm{pH} 3.8$. Isocratic elution provided a better elution profile in this study as compared to gradient mode. Positive baseline drift was observed when gradient elution was used, due to the differences in the absorbance properties between the mobile phases. Utilisation of buffer system as HPLC mobile phase could control the ionisation and retention of analytes. It is extremely useful in stability indicating method where the impurities or interfering compounds are ionisable. Optimising the acidity and buffer concentration of the mobile phase could also ensure consistent separation and prevent peak tailing. ${ }^{18}$

\section{Method validation}

Our study was validated in terms of specificity, linearity, accuracy, repeatability and robustness, as per ICH guidelines. ${ }^{13}$

\section{Calibration curve and linearity, Limit of detection (LOD) and quantification (LOQ)}

The calibration curve was established by plotting the peak area ratio of flibanserin vs the concentration of flibanserin standards. Linearity was evaluated in triplicates using seven concentrations $(1-20 \mu \mathrm{g} / \mathrm{mL})$. Regression equation was $\mathrm{y}=24132 \mathrm{x}-869.96$ and it showed good linearity, $R^{2}=0.9993$. LOD and LOQ calculated was $0.0109 \mu \mathrm{g} / \mathrm{mL}$ and $0.0330 \mu \mathrm{g} / \mathrm{mL}$, respectively (Table 1).

\section{Accuracy, precision and repeatability}

A recovery study was performed to calculate accuracy. The mean recovery was $99.37-100.75 \%$, \%RSD was below $2.0 \%$. Precision measures the reproducibility

\begin{tabular}{|c|c|c|}
\hline \multicolumn{3}{|c|}{$\begin{array}{c}\text { Table 1: Comparison of retention time, linearity, } \\
\text { repeatability, LOD and LOQ of developed and } \\
\text { reference method. }\end{array}$} \\
\hline Parameters & Developed system & Reference system \\
\hline $\begin{array}{c}\text { HPLC mobile } \\
\text { phases }(v / v)\end{array}$ & $\begin{array}{c}\text { Ammonium acetate } \\
\text { buffer: Acetonitrile } \\
(40: 60), \mathrm{pH} 3.8\end{array}$ & $\begin{array}{c}\text { Formic } \\
\text { Acid:Acetonitrile } \\
(40: 60), \mathrm{pH} 3.8\end{array}$ \\
\hline $\begin{array}{c}\text { Retention time } \\
(\text { min })\end{array}$ & 5.1 & 5.4 \\
\hline $\begin{array}{c}\text { Linearity } \\
\text { Linear equation }\end{array}$ & $\mathrm{y}=24132 \mathrm{x}-869.96$ & $\mathrm{y}=15843 \mathrm{x}-4144.4$ \\
\hline $\begin{array}{c}\text { Correlation } \\
\text { coefficient }(r)\end{array}$ & 0.9993 & 0.9989 \\
\hline $\begin{array}{c}\text { Repeatability } \\
\text { Mean recovery } \% \\
(n=3)\end{array}$ & $99.37-100.75$ & $99.17-101.83$ \\
\hline$\%$ RSD; NMT $2.0 \%$ & $<2 \%$ & $<2 \%$ \\
\hline LOD $(\mu \mathrm{g} / \mathrm{mL})$ & 0.0109 & 0.0135 \\
\hline LOQ $(\mu \mathrm{g} / \mathrm{mL})$ & 0.0330 & 0.0409 \\
\hline
\end{tabular}




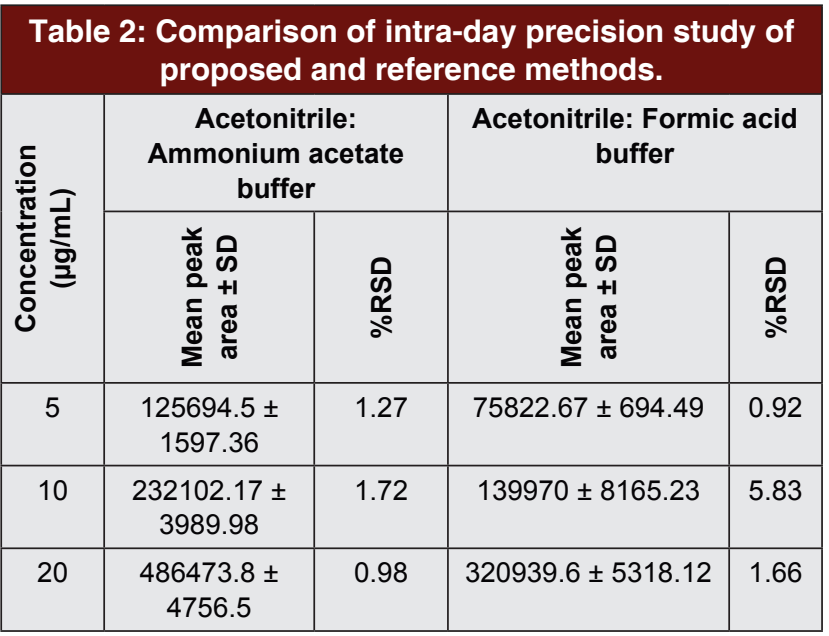

\begin{tabular}{|c|c|c|c|c|}
\hline \multicolumn{4}{|c|}{ Table 3: Comparison of inter-day precision study of } \\
proposed and reference methods \\
\hline Day & $\begin{array}{c}\text { Acetonitrile: Ammonium } \\
\text { acetate buffer }\end{array}$ & $\begin{array}{c}\text { Acetonitrile: Formic acid } \\
\text { buffer }\end{array}$ \\
\cline { 2 - 5 } & $\begin{array}{c}\text { Mean peak area } \\
\pm \text { SD }\end{array}$ & \%RSD & $\begin{array}{c}\text { Mean peak area } \\
\pm \text { SD }\end{array}$ & \%RSD \\
\hline 1 & $\begin{array}{c}490098.77 \pm \\
4523.71\end{array}$ & 0.92 & $\begin{array}{c}314574.4 \pm \\
17437.69\end{array}$ & 5.54 \\
\hline 2 & $503086.83 \pm$ & 1.61 & $308756.93 \pm$ \\
9096.73 & & 3753.71 & 3.16 \\
\hline 3 & $495299 \pm$ & 1.22 & $327880.43 \pm$ & 9.72 \\
& 6057.42 & & 31867.46 & \\
\hline
\end{tabular}

\begin{tabular}{|c|c|c|c|c|c|}
\hline \multicolumn{3}{|c|}{ Table 4: Comparison of robustness of developed and reference methods. } \\
\hline \multirow{2}{*}{ Parameter } & Condition & \multicolumn{2}{|c|}{ Acetonitrile: Ammonium acetate buffer } & \multicolumn{2}{|c|}{ Acetonitrile: Formic acid buffer } \\
\cline { 2 - 6 } & & Mean peak area \pm SD & \%RSD & Mean peak area \pm SD & $\% R S D$ \\
\hline \multirow{2}{*}{$\begin{array}{c}\text { Flow rate } \\
( \pm 0.1 \mathrm{~mL} / \mathrm{min})\end{array}$} & 0.9 & $236207.67 \pm 573.31$ & 0.24 & $148461 \pm 2989.55$ & 2.01 \\
\cline { 2 - 6 } & 1.0 & $240307.33 \pm 3455.42$ & 1.44 & $151226.33 \pm 5609.17$ & 3.71 \\
\cline { 2 - 6 } & 1.1 & $239332.33 \pm 2790.07$ & 1.17 & $151163.33 \pm 4307.09$ & 2.85 \\
\hline \multirow{2}{*}{$\begin{array}{c}\text { Detection wavelength } \\
( \pm 2 \mathrm{~nm})\end{array}$} & 248 & $238126 \pm 1262.85$ & 0.53 & $146737.67 \pm 1158.38$ & 0.79 \\
\cline { 2 - 6 } & 250 & $240307.33 \pm 3455.42$ & 1.44 & $151226.33 \pm 5609.17$ & 3.71 \\
\cline { 2 - 6 } & 252 & $238349.67 \pm 1520.94$ & 0.64 & $151218.33 \pm 1940.08$ & 1.28 \\
\hline $\begin{array}{c}\text { Mobile phase } \\
\text { composition ratio }\end{array}$ & $62: 38$ & $239585 \pm 749.03$ & 0.31 & $150085.33 \pm 5937.89$ & 3.96 \\
\cline { 2 - 6 } & $60: 40$ & $240307.33 \pm 3455.42$ & 1.44 & $151226.33 \pm 5609.17$ & 3.71 \\
\cline { 2 - 6 } & $58: 42$ & $239320.33 \pm 546.81$ & 0.22 & $151255.67 \pm 3979.4$ & 2.63 \\
\hline
\end{tabular}

and repeatability of the independent test results under stipulated conditions. Three runs were analyzed individually to establish the intra-day and inter-day precision. The working standards used ranged from $5-20 \mu \mathrm{g} / \mathrm{mL}$ and $\%$ RSD was calculated. The \%RSD values for intra-day and inter-day precision values were less than 2.0\%. \%RSD for intra-day ranged $0.98-1.72 \%$ (Table 2), while inter-day ranged $0.92-1.61 \%$ (Table 3). Low $\%$ RSD in accuracy and precision studies indicated that the method had promising accuracy, precision, reproducibility and repeatability.

\section{Robustness}

Robustness of an analytical procedure measures the estimation of capacity to remain unaffected by minor, but deliberate variation in the method parameters. ${ }^{19}$ This is an indication of its reliability for routine analysis. The developed method was robust as the test solutions were not affected by varying the conditions. $\%$ RSD was remained below $2.0 \%$ (Table 4 ).

\section{Forced degradation}

Forced degradation study was performed on flibanserin bulk drug under acidic, alkaline and oxidative conditions at $25^{\circ} \mathrm{C}$. Drugs could be degraded at slower rate at ambient temperature. Therefore, higher temperature was used to accelerate the degradation of drugs, to evaluate their stability under certain stress conditions. Accelerated degradation at higher temperature $\left(50^{\circ} \mathrm{C}\right.$ and $\left.70^{\circ} \mathrm{C}\right)$ was performed when no significant degradation was noticed at $25^{\circ} \mathrm{C}$ after $24 \mathrm{hr}$.

From our study, flibanserin remained stable under acidic, alkaline, radical and transition metal oxidations at $25^{\circ} \mathrm{C}$. Exception was significant degradation was observed in $\mathrm{H}_{2} \mathrm{O}_{2}$ oxidation. Reduction of flibanserin concentration over time was noticed and one impurity peak $(\mathrm{R} t=5.6 \mathrm{~min})$ was noticed in the chromatogram (Figure 1). The LC-MS analysis performed showed that two impurities were detected and both had $\mathrm{m} / \mathrm{z} 407.17$ (Figure 2). Our findings were in agreement to others which have reported on the oxidation of flibanserin in the 
(a)

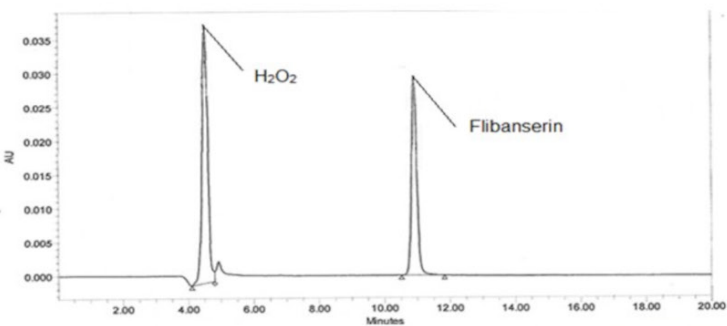

(b)

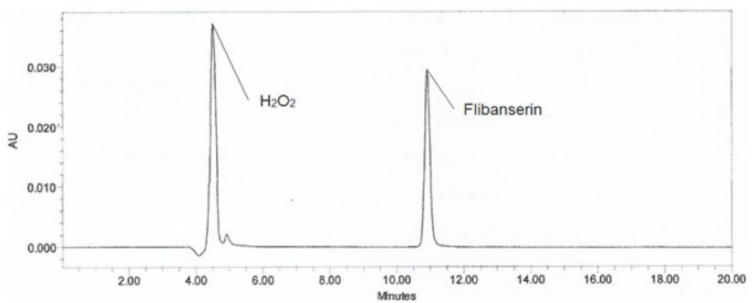

(c)

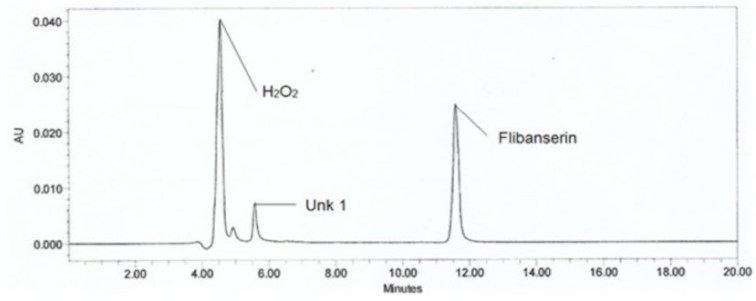

(d)

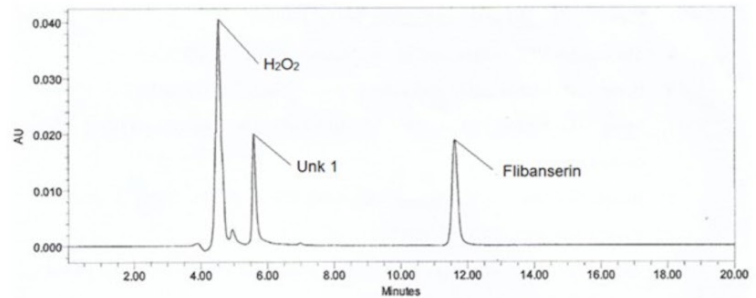

(e)

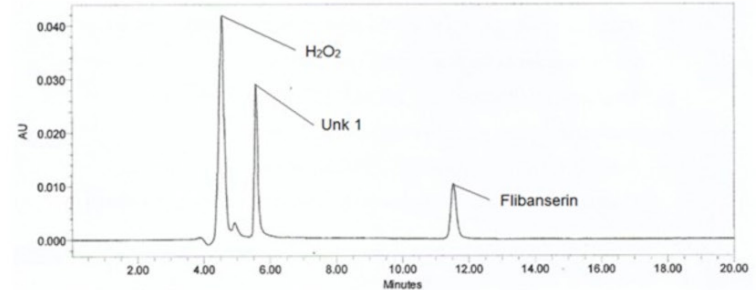

(f)

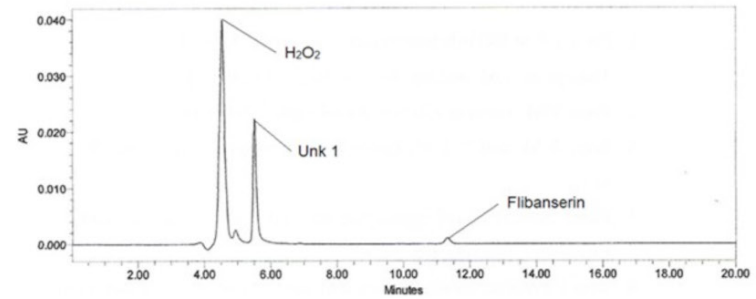

Figure 1: Chromatogram of $\mathrm{H}_{2} \mathrm{O}_{2}$ degraded samples at (a) $0 \mathrm{hr}$, (b) $0.5 \mathrm{hr}$, (c) 1 hr, (d) 2 hr, (e) 4 hr, and (f) 8 hr. (Unk 1 represents Unknown 1).

presence of $\mathrm{H}_{2} \mathrm{O}_{2}$. Sharma et al. ${ }^{20}$ recently reported four oxidative metabolites from flibanserin, with $\mathrm{m} / \mathrm{z} 407.1696$, 407.1672, 407.1686, 407.1691, which were similar to our study. Further analysis on the oxidative metabolites
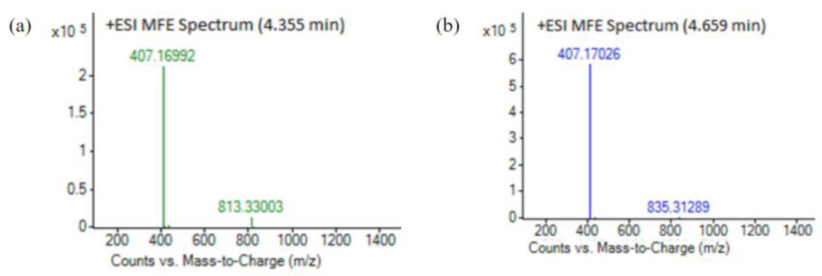

Figure 2: Peak homogeneity spectrum of flibanserin impurities, from $\mathrm{H}_{2} \mathrm{O}_{2}$ degradation. (a)

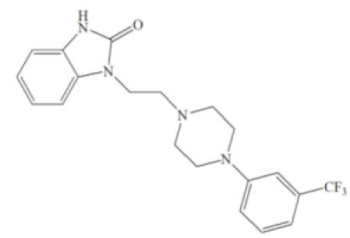

(c)

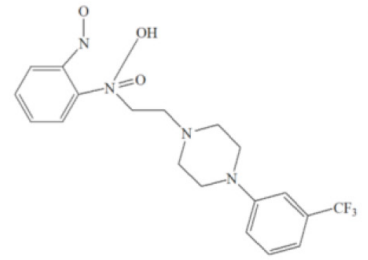

(b)
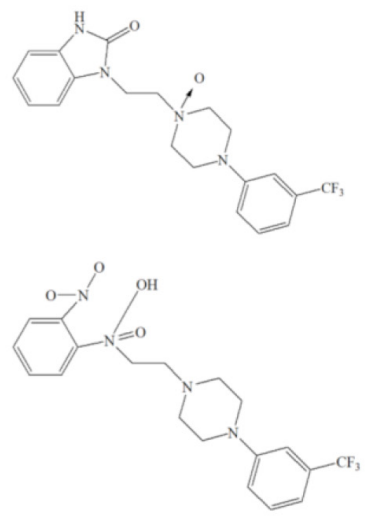

Figure 3: Structure of (a) Flibanserin and (b-d) N-oxide impurities.

\section{Table 5: Proposed models of flibanserin degradation} kinetics under $\mathrm{H}_{2} \mathrm{O}_{2}$ and radical oxidation.

\begin{tabular}{|c|c|c|}
\hline Reaction order & Linear equation & $r^{2}$ \\
\hline \multicolumn{3}{|c|}{$\mathrm{H}_{2} \mathrm{O}_{2}$ oxidation (at $25^{\circ} \mathrm{C}$ ) } \\
\hline Zero-order & $\begin{aligned} y= & -0.7665 x+ \\
& 9.2409\end{aligned}$ & 0.9721 \\
\hline First-order & $\begin{array}{c}y=-0.1254 x+ \\
2.2515\end{array}$ & 0.9963 \\
\hline Second-order & $y=0.022 x+0.0982$ & 0.9870 \\
\hline \multicolumn{3}{|c|}{ AIBN oxidation (at $50^{\circ} \mathrm{C}$ ) } \\
\hline Zero-order & $\begin{array}{c}y=-1.6677 x+ \\
8.7776\end{array}$ & 0.9807 \\
\hline First-order & $\begin{array}{c}y=-0.3214 x+ \\
2.2363\end{array}$ & 0.9993 \\
\hline Second-order & $y=0.0698 x+0.0854$ & 0.9734 \\
\hline \multicolumn{3}{|c|}{$\mathrm{FeCl}_{3}$ oxidation (at $75^{\circ} \mathrm{C}$ ) } \\
\hline Zero-order & $\begin{aligned} y= & -0.8203 x+ \\
& 9.8364\end{aligned}$ & 0.9468 \\
\hline First-order & $y=0.0236 x+0.0829$ & 0.7860 \\
\hline Second-order & $\begin{array}{c}y=-\frac{0.1336 x+}{2.3446}\end{array}$ & 0.8732 \\
\hline
\end{tabular}

was performed using UHPLC-Q-TOF-MS/MS, and the possible N-oxide structures were proposed (Figure 3(b)). Additional spectral information such as hydrogen deuterium exchange (H/D exchange) study and nuclear 
magnetic resonance (NMR) spectroscopy would be required for the structural confirmation. Besides, Ahmed et al. ${ }^{21}$ had also reported that flibanserin was degraded by $30 \% \mathrm{H}_{2} \mathrm{O}_{2}$ heating at $100^{\circ} \mathrm{C}$, and yielded two $\mathrm{N}$-oxide products. The amide bond in benzimidazole ring of flibanserin was hydrolysed and the cleavage had yielded carboxylic acid groups and addition of oxygen atom(s) to nitrogen (Figure 3(c) and 3(d)). The N-oxide degradation impurities could be genotoxic and act as reactive metabolite. ${ }^{20}$ It was reported that $\mathrm{N}$-oxides could result in deoxyribonucleic acid (DNA) damage, cause genetic mutation, and the reaction between

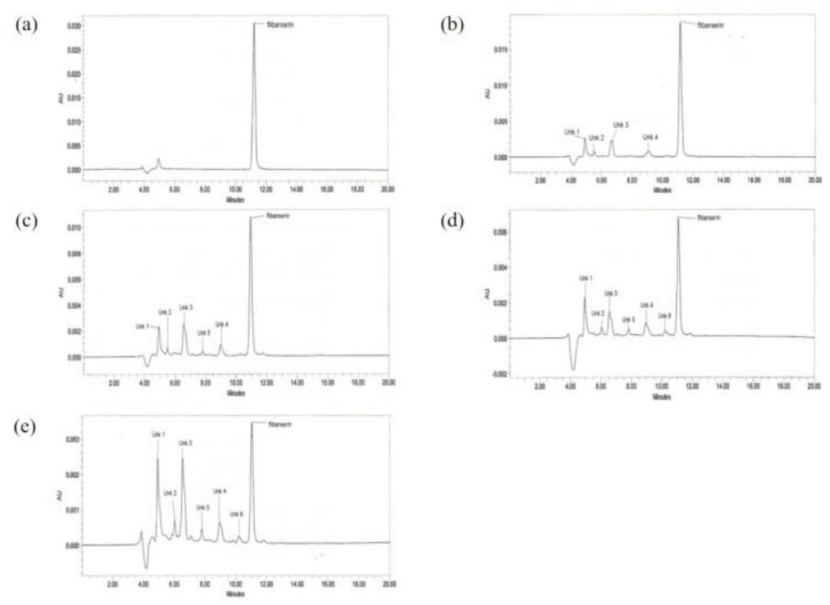

Figure 4: Chromatogram of AIBN degraded samples with thermal treatment at (a) 0 day, (b) 1 day, (c) 3 days, (d) 5 days, and (e) 7 days. (Unk 1 represents Unknown 1; Unk 2 represents Unknown 2; Unk 3 represents Unknown 3; Unk 4 represents Unknown 4; Unk 5 represents Unknown 5; Unk 6 represents Unknown 6).

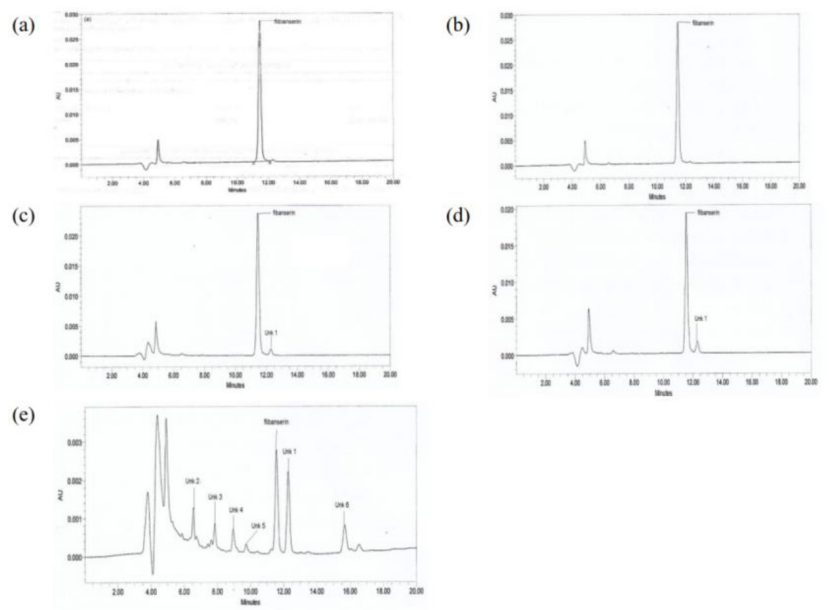

Figure 5: Chromatogram of $\mathrm{FeCl}_{3}$ degraded samples with thermal treatment at (a) 0 day, (b) 1 day, (c) 2 days, (d) 4 days and (e) 7 days. (Unk 1 represents Unknown 1; Unk 2 represents Unknown 2; Unk 3 represents Unknown 3; Unk 4 represents Unknown 4; Unk 5 represents Unknown 5; Unk 6 represents Unknown 6). oxygen and superoxide and nitric oxide could lead to genotixic effects. ${ }^{22,23}$

Degradation kinetics aimed to predict the intrinsic stability of flibanserin in order to anticipate problems that may arise. Our degradation kinetics showed that the model that best explained the degradation of flibanserin by $\mathrm{H}_{2} \mathrm{O}_{2}$ was the first-order model, with the best $\mathrm{r}^{2}$ (Table 5). The $t_{1 / 2}$ of the drug is important as a guidance in drug formulation and storage conditions. Shelf life $\left(\mathrm{t}_{90}\right.$ or $\left.\mathrm{t}_{95}\right)$ is the time required by the drug to reduce to $90 \%$ or $95 \%$ of its original concentration. The halflife of flibanserin under $\mathrm{H}_{2} \mathrm{O}_{2}$ stress was $5.5 \mathrm{hr}$, and the $\mathrm{t}_{90}$ or $\mathrm{t}_{95}$ was 50 mins and 25 mins, respectively. This showed that flibanserin was extremely unstable under this oxidative condition.

Accelerated degradation at higher temperature was performed in acidic, alkaline, radical initiator and transition metal oxidations. Flibanserin remained stable under acidic and basic conditions up to $70^{\circ} \mathrm{C}$. Significant degradation was noticed in oxidation by AIBN radical initiator and $\mathrm{FeCl}_{3}$ at higher temperatures. Six degradation impurities were spotted in both treatments (Figure 4 and Figure 5). Degradation kinetics showed that the model that best explain the oxidative degradation by AIBN also followed a first-order kinetic $\left(R^{2}=0.9993\right)$ (Table 5). The degradation was rapid at the initial rate and slowed down after that. The shelf life and half-life determined under the condition were $\mathrm{t}_{90}=7.8 \mathrm{hr}, \mathrm{t}_{95}=3.8 \mathrm{hr}$, and $\mathrm{t}_{1 / 2}=2$ days at $50^{\circ} \mathrm{C}$.

The degradation kinetics of $\mathrm{FeCl}_{3}$ was best fitted to the zero-order kinetic, as the $R^{2}$ value $\left(R^{2}=0.9468\right)$ for this model was the highest (Table 5). The shelf life and halflife determined under the transition metal oxidation condition were $\mathrm{t}_{90}=27.9 \mathrm{hr}, \mathrm{t}_{95}=14.0 \mathrm{hr}$, and $\mathrm{t}_{1 / 2}=6$ days at $70^{\circ} \mathrm{C}$.

The physicochemical properties of pharmaceutical excipients could result in formulation instability that could potentially disrupt the quality and efficacy. Interaction between drug substances and excipients and their incompatibilities could be a serious concern in pharmaceutical industries. The selection of appropriate excipients which have good mutual compatibility with drug substances in the formulation is extremely important in developing a quality product that sustains its desired properties throughout the shelf-life period. From this study, a few pharmaceutical excipients which were included in the flibanserin formulation were not recommended. Excipients such as hydroxypropyl cellulose, polyethylene glycol 400, povidone, and polysorbate 80 were found to contain substantial concentration of hydroperioxides (HPOs) should be caution in flibanserin drug products due to its 
oxidative sensitivity. It was reported that the film-coated flibanserin tablet contains povidone and copovidone as binding agents. ${ }^{12}$ The presence of peroxide impurities in excipients (povidone and crospovidone) were able to trigger oxidation reaction with oxygen via the freeradical mechanism or direct oxidation reaction of tertiary amine by peroxide. ${ }^{24}$ These binding agents could potentially react with flibanserin and lead to drug degradation. This was supported by the study conducted by Hartauer and Arbuthnot ${ }^{24}$ which reported on the effects of povidone and crospovidone on the stability of raloxifene hydrochloride in tablets. The drug-excipient interaction between povidone and crospovidone with raloxifene hydrochloride was noticed, where the peroxides produced by the excipients (povidone and crospovidone) reacted with drug substance and yielded N-oxide impurities. Similar finding was also reported on the $\beta$-blocker drugs-excipient interaction. Prachi et al..$^{25}$ investigated the compatibility of several ingredients, including labetalol, atenolol, propanol hydrochloride, hydrochloride, bisoprolol fumarate, metoprolol succinate, and carvedilol with the povidone. Peroxide from povidone could affect the stability of selected $\beta$-blockers where the degradation was due to peroxides that exist as an impurity in povidone. Physical and chemical changes were detected in the drugs. It was proposed that the interaction of drug substances with povidone could be either by free radical chain reaction mechanism with oxygen or by direct secondary amine oxidation due to peroxide. With these supporting literatures, the selection and addition of excipients should be meticulously evaluated.

The addition of antioxidants into the pharmaceutical formulations could potentially inhibit oxidative reaction. The antioxidants could react with the peroxides and scavenge free radicals to inhibit any possible oxidative process. $^{6}$ A common example of antioxidant which could be considered to include in the pharmaceutical formulations is ethylenediaminetetraacetic acid (EDTA) which could bind to the peroxides present in the formulation. Besides, povidone and copovidone could be replaced with other binding agents free from peroxide impurities such as corn starch.

Besides povidone, it was reported that flibanserin drug formulation may also contain microcrystalline cellulose as filler/dry binder. ${ }^{12}$ Microcrystalline cellulose could possibly react with flibanserin and resulted in degradation impurities. The radical impurities in microcrystalline cellulose could also potentially trigger oxidation reaction via free-radical mechanism with oxygen. Drug incompatibility microcrystalline cellulose added as excipient in the pharmaceutical formulations had been reported. ${ }^{6}$ Drugs which were reported to be incompatible with microcrystalline cellulose were Elzasonan (CP448187), BMS-A and Vigabatrin. Impurities were detected in the excipient. Therefore, the stability of flibanserin upon the addition of microcrystalline cellulose into the formulation should also be re-evaluated for drug safety reason.

It was reported that flibanserin formulation consisted of polyethylene glycol (PEG) as emulsifier or plasticizer. ${ }^{26}$ Metal ions were able to trigger oxidation reaction which lead to the formation of low-molecular-weight aldehydes and organic acids in PEG. It involved oxygen by free-radical mechanism. ${ }^{27}$ These reactive impurities in PEG could react with flibanserin and resulted in degradation impurities. Drugs which were reported to be incompatible with PEG were varenicline and BMS203452. Impurities were detected in the excipient. ${ }^{6}$ Antioxidants such as butylated hydroxytoluene (BHT) and butylated hydroxyanisole (BHA), propyl gallate vitamin E TPGS and sodium metabisulfite were effective in preventing oxidative reaction whereas ascorbic acid and acetic acid were not. ${ }^{27}$

\section{CONCLUSION}

The quality of active pharmaceutical ingredients is extremely important for patient's safety. The safety and efficacy of drug products may be affected by the presence of degradation impurities. In this study, the stability indicating method was developed using RP-HPLC. A rapid, specific, sensitive, accurate and precise, robust and reproducible isocratic HPLC method are developed. The method validation showed that the method is linear, precise, accurate and specific to the drug in presence of degradation impurities. Flibanserin was found to be susceptible to oxidative degradation: $\mathrm{H}_{2} \mathrm{O}_{2}$ at room temperature conditions, and $\mathrm{FeCl}_{3}$ and AIBN at accelerated stress conditions $\left(50^{\circ} \mathrm{C}\right.$ and above). Oxidation of flibanserin under $\mathrm{H}_{2} \mathrm{O}_{2}$ had yielded two impurities with $\mathrm{m} / \mathrm{z}$ 407.17. It was deduced that the oxidative metabolites were N-oxide. Degradation kinetic showed that flibanserin degradation followed the first order reaction for $\mathrm{H}_{2} \mathrm{O}_{2}$ and $\mathrm{AIBN}$, and zero order reaction for $\mathrm{FeCl}_{3}$. The suggested method can be used for quality controland routine analysisof flibanserin in laboratories.

\section{Author Contributions}

YL Chew conceived the idea; HK Lee and MA Khor contributed to the data acquisition, analysis, and interpretation of data. YL Chew, HK Lee and MA Khor wrote the manuscript; KB Liew, BVS Lokesh and GA 
Akowuah reviewed the paper and provided comments, all authors reviewed the manuscript.

\section{ACKNOWLEDGEMENT}

The author are thankful to UCSI University for supporting the work in terms of facilities and funding (Proj-In-FPS-012 and Proj-2019-In-FPS-020).

\section{CONFLICT OF INTEREST}

The authors declare no conflict of interest.

\section{ABBREVIATIONS}

AIBN: 1,1'-azobis(cyclohexane-carbonitrile); $\mathbf{N a O H}$ : anhydrous sodium hydroxide; $\mathbf{H C l}$ : Hydrochloric acid; RP-HPLC: Reversed phase-High Performance Liquid Chromatography; $\mathbf{H}_{2} \mathbf{O}_{2}$ : hydrogen peroxide; FTIR: Fourier Transformer Infrared; $\mathbf{5 - H T _ { 1 A }}$ : 5-hydroxytryptamine $1_{\mathrm{A}} ; \mathbf{5}-\mathbf{H T}_{2 \mathrm{~A}}$ : 5-hydroxytryptamine 2 ; USFDA: United State Food and Drug Administration; LOD: limit of detection; LOQ: limit of quantification; API: active pharmaceutical ingredients; UV: Ultra-violet; v/v: volume/volume; RSD: relative standard deviation; LC-MS: liquid chromatography coupled with mass spectrometry; ICH: International Council for Harmonisation of Technical Requirements for Pharmaceuticals for Human Use; NMR: nuclear magnetic resonance; DNA: deoxyribonucleic acid; $\mathbf{t}_{\mathbf{9 0}}$ : time required by the drug to reduce to $90 \%$ of its original concentration; $\mathbf{t}_{95}:$ time required by the drug to reduce to $95 \%$ of its original concentration; $\mathbf{t}_{1 / 2}$ : half-life; HPOs: hydroperioxides; EDTA: ethylenediaminetetraacetic acid; PEG: polyethylene glycol; BHA: butylated hydroxyanisole; $\mathbf{F e C l}_{3}$ : anhydrous ferric (III) chloride; $\mathrm{CuSO}_{4}$ : copper (II) sulfate pentahydrate; MS: mass spectrometry; UHPLC-Q-TOF-MS: ultra-high performance liquid chromatography-quadrupole timeof-flight mass spectrometry; $\lambda_{\text {max }}$ : maximum absorption wavelength; $\mathbf{R}_{\mathrm{t}}$ : retention time; $\boldsymbol{\sigma}$ : standard deviation of intercept.

\section{REFERENCES}

1. Singh S, Junwal M, Modhe G, Tiwari H, Kurmi M, Parashar N, et al. Forced degradation studies to assess the stability of drugs and products. TrAC Trends Anal Chem. 2013;49:71-88. doi: 10.1016/j.trac.2013.05.006.

2. Blessy MR, Patel RD, Prajapati PN, Agrawal YK. Development of forced degradation and stability indicating studies of drugs-A review. J Pharm Anal. 2014;4(3):159-65. doi: 10.1016/j.jpha.2013.09.003, PMID 29403878.

3. Zhou D, Porter WR, Zhang GG. Drug stability and degradation studies. Developing Solid Oral Dosage Forms. Elsevier; 2009;87-124.

4. Singh R, Rehman ZU. Current trends in forced degradation study for pharmaceutical product development. J Pharm Educ Res. 2012;3(1):54.
5. Loftsson T. Drug stability for pharmaceutical scientists. Academic Press; 2014.

6. Wu Y, Levons J, Narang AS, Raghavan K, Rao VM. Reactive impurities in excipients: profiling, identification and mitigation of drug-excipient incompatibility. AAPS Pharm Sci Tech. 2011;12(4):1248-63. doi: 10.1208/ s12249-011-9677-z, PMID 21948318.

7. Ravisankar P, Swathi V, Srinivasa Babu P, Shaheem Sultana Md GS. Current trends in performance of forced degradation studies and stability indicating studies of drugs. IOSR JPBS. 2017;12(6):17-36.

8. Kumar SD, Kumar DH. Importance of RP-HPLC in analytical method development: A review. Int J Pharm Sci Res. 2012;3(12):4626.

9. English C, Muhleisen A, Rey JA. Flibanserin (Addyi): the first FDA-approved treatment for female sexual interest/arousal disorder in premenopausal women. P T. 2017;42(4):237-41. PMID 28381915.

10. Katz M, DeRogatis LR, Ackerman R, Hedges P, Lesko L, Garcia Jr M, et al. BEGONIA trial investigators. Efficacy of flibanserin in women with hypoactive sexual desire disorder: results from the BEGONIA trial. J Sex Med. 2013;10(7):1807-15. doi: 10.1111/jsm.12189, PMID 23672269.

11. Stahl SM. Mechanism of action of flibanserin, a multifunctional serotonin agonist and antagonist (MSAA), in hypoactive sexual desire disorder. CNS Spectr. 2015;20(1):1-6. doi: 10.1017/S1092852914000832, PMID 25659981.

12. Friedl T, Radtke GBE. Pharmaceutical compositions containing flibanserin. Google Pat. 2015.

13. Guideline IHT. Validation of analytical procedures: text and methodology Q2. International conference on harmonization, Geneva, Switzerland; 2005. Vol. R1.

14. Low MY, Li L, Ge X, Kee CL, Koh HL. Isolation and structural elucidation of flibanserin as an adulterant in a health supplement used for female sexual performance enhancement. J Pharm Biomed Anal. 2012;57:104-8. doi: 10.1016/j.jpba.2011.08.027, PMID 21955644.

15. Poplawska M, Blazewicz A, Zolek P, Fijalek Z. Determination of flibanserin and tadalafil in supplements for women sexual desire enhancement using high-performance liquid chromatography with tandem mass spectrometer, diode array detector and charged aerosol detector. J Pharm Biomed Anal. 2014;94:45-53. doi: 10.1016/j.jpba.2014.01.021, PMID 24531007.

16. Hua $Y$, Jenke D. Increasing the sensitivity of an LC-MS method for screening material extracts for organic extractables via mobile phase optimization. J Chromatogr Sci. 2012;50(3):213-27. doi: 10.1093/chromsci/bmr049, PMID 22337798.

17. Chew YL, Lee HK, Bontha Venkata SL. New stability indicating method for estimation of purity of flibanserin active pharmaceutical ingredient. Indian Drugs. 2020;57(4):40-4. doi: 10.53879/id.57.04.12147.

18. Kongkiatpaiboon S, Duangdee N, Chewchinda S, Poachanukoon O, Amnuaypattanapon K. Development and validation of stability indicating HPLC method for determination of adrenaline tartrate. J King Saud Univ Sci. 2019 Jan 1;31(1):48-51. doi: 10.1016/j.jksus.2017.05.016.

19. Patel J, Chokshi P, Mashru R. Validation of stability indicating method and degradation kinetic study of apremilast. J Drug Delivery Ther. 2020;10(2):76-85. doi: 10.22270/jddt.v10i2.3964.

20. Sharma MK, Shah RP, Sengupta P. Amalgamation of stress degradation and metabolite profiling in rat urine and feces for characterization of oxidative metabolites of flibanserin using UHPLC-Q-TOF-MS/MS, H/D exchange and NMR technique. J Chromatogr B Analyt Technol Biomed Life Sci. 2020;1139:121993. doi: 10.1016/j.jchromb.2020.121993.

21. Ahmed RM, Abdallah IA. Determination of flibanserin in the presence of confirmed degradation products by a third derivative emission spectrofluorometric method: application to pharmaceutical formulation. Spectrochim Acta A Mol Biomol Spectrosc. 2020;225:117491. doi: 10.1016/j. saa.2019.117491.

22. Phoa N, Epe B. Influence of nitric oxide on the generation and repair of oxidative DNA damage in mammalian cells. Carcinogenesis. 2002;23(3):469-75. doi: 10.1093/carcin/23.3.469, PMID 11895862.

23. Felley-Bosco E. Role of nitric oxide in genotoxicity: Implication for carcinogenesis. Cancer Metastasis Rev. 1998;17(1):25-37. doi: 10.1023/a:1005948420548, PMID 9544421.

24. Hartauer KJ, Arbuthnot GN, Baertschi SW, Johnson RA, Luke WD, Pearson NG, et al. Influence of peroxide impurities in povidone and crospovidone on the stability of raloxifene hydrochloride in tablets: identification and control of 
an oxidative degradation product. Pharm Dev Technol. 2000;5(3):303-10. doi: 10.1081/pdt-100100545, PMID 10934729.

25. Prachi S, Komal C, Priti MJ. Influence of peroxide impurities in povidone on the stability of selected $\beta$-blockers with the help of HPLC. AAPS Pharm Sci Tech. 2017;18(7):2410-7. doi: 10.1208/s12249-017-0716-2, PMID 28155135.
26. Friedl T, Radtke G. Pharmaceutical compositions containing flibanserin. Google Pat. 2004.

27. Hemenway JN, Carvalho TC, Mantri RV, Wu Y, Levons JK, et al. Reactive impurities in PEG: A case study. In: Ajit SN, Sai HSB, editors. Excipient applications in formulation design and drug delivery. Springer; 2015;67-91.

\section{PICTORIAL ABSTRACT}

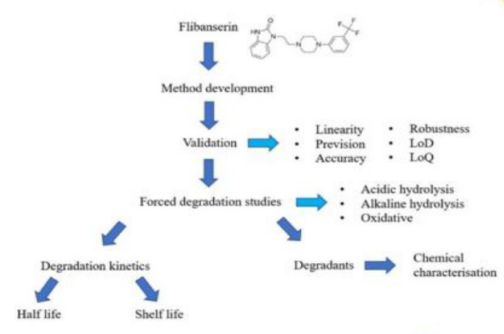

\section{About Authors}

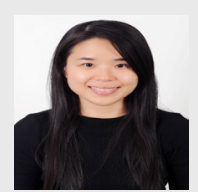

Dr Yik-Ling Chew obtained her PhD from Monash University, Australia in 2011. Currently she is working as an Assistant Professor in the Faculty of Pharmaceutical Sciences, UCSI University, Kuala Lumpur, Malaysia. Her research specialisations include natural products chemistry, and various biological activities in tropical plants, including anticancer, antimicrobial, antioxidants and anti-inflammatory. She has published research and review articles in renowned journals and presented her work in both national and international conferences.

\section{SUMMARY}

Flibanserin is the first approved drug by United State Food and Drug Administration (USFDA) for the treatment of female sexual interest/arousal disorder of any severity. The stability of flibanserin in various stress conditions remained unknown so far and no scientific report had reported till today. This study optimized the stability indicating method using RP-HPLC as per ICH guideline, and evaluated the stability of flibanserin under various forced degradation conditions, including acidic, alkaline and oxidative conditions $\left(\mathrm{H}_{2} \mathrm{O}_{2}, \mathrm{AIBN}\right.$ and $\mathrm{FeCl}_{3}$ ). The order of the degradation kinetics, halflife and shelf life of flibanserin under certain stress conditions were carefully determined. It was found that flibanserin could be degraded under $\mathrm{H}_{2} \mathrm{O}_{2}$ condition, where impurities were detected in the HPLC. From the LC-MS analysis, two N-oxide impurities were identified. The degradation kinetic of flibanserin under oxidative conditions had also been revealed, and half-life and shelf life of flibanserin under respective stress conditions were determined. From our study, it was highlighted that some excipients present in the flibanserin formulation may possess potential degradation risk to the drug, and potential replacement excipients had also been suggested and highlighted for better product formulation.

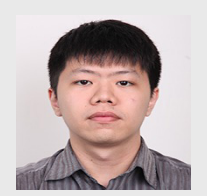

Hon-Kent Lee graduated his Master of Science in Pharmaceutical Chemistry from UCSI University, Kuala Lumpur, Malaysia and Bachelor of Science (Hons) Industrial Chemistry from Universiti Malaysia Sabah. He is specialised in analytical chemistry and pharmaceutical analysis.

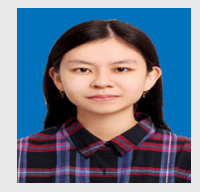

Mei-Ann Khor graduated her Bachelor of Pharmacy (Hons) degree from UCSI University, Kuala Lumpur, Malaysia. She is a practising pharmacist, currently working in Seberang Prai hospital. She had published 1 review article and 1 book chapter.

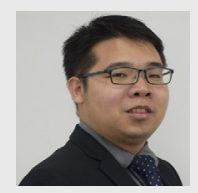

Dr Kai-Bin Liew is the Head of Department of Pharmaceutical Technology and Industry at University of Cyberjaya. He has experience in various pharmaceutical related fields including research and development, product development, bioequivalence study, analytical chemistry, regulatory affair and public health pharmacy. He has published more than 50 publications in international journals and repeatedly invited as speaker to deliver speeches in neighboring countries. He has also supervised research projects for both undergraduate and postgraduate pharmacy students. His research areas focus on the novel drug delivery system, nanoparticles, orally disintegrating dosage forms, bioequivalence study and self microemulsifying system. 


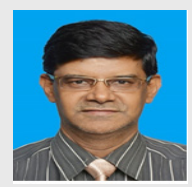

Dr Bontha Venkata Subrahmanya Lokesh is currently associated with the Faculty of Pharmacy, Universiti Malaya since 2021. He has been working in the academic industry for the past 23 years abroad. He has also produced 3 years of pharmaceutical industry experience in Analytical Research and Development in India. He is a doctorate in Pharmaceutical Sciences (Ph.D.) from Andhra University, India. He has been actively involved in research projects and secured grants in Malaysia. He has 21 publications in reputed international journals with impact factors. He is specialized in the field of pharmaceutical chemistry and pharmaceutical analysis. His specific research area is in analytical method development, drug synthesis, biological activity, molecular docking, and chemometrics.

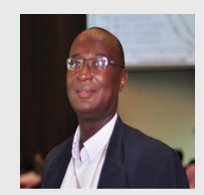

Dr Gabriel Akyirem Akowuah is currently working as Associate Professor of Pharmaceutical Chemistry and the Head of Pharmaceutical Chemistry Department of the Faculty of Pharmaceutical Sciences at UCSI University, Kuala Lumpur, Malaysia. Dr. Akowuah received his Ph.D. from the Faculty of Pharmaceutical Sciences of the Universiti Sains Malaysia in 2005 majoring in Pharmaceutical Chemistry. Dr Akowuah is author of over 60 publications and 30 presentations in various areas of pharmaceutical, phytochemical and biomedical analyses, toxicology, pharmacokinetic and bioavailability studies.

Cite this article: Chew Y, Lee H, Khor M, Liew K, Lokesh BVS, Akowuah GA. Forced Degradation of Flibanserin Bulk Drug: Development and Validation of Stability Indicating RP-HPLC Method. Indian J of Pharmaceutical Education and Research. 2022;56(1):32-42. 